\title{
3D-Finite element modeling of lead rubber bearing using high damping material
}

\author{
Ahmad Basshofi Habieb ${ }^{1}$, Tavio Tavio ${ }^{2 *}$, Gabriele Milani ${ }^{1}$, and Usman Wijaya ${ }^{3}$ \\ ${ }^{1}$ Department of Civil Engineering, Politecnico di Milano, Milano, Italy \\ ${ }^{2}$ Department of Civil Engineering, Institut Teknologi Sepuluh Nopember (ITS), Surabaya, Indonesia \\ ${ }^{3}$ Department of Civil Engineering, Universitas Tarumanagara, Jakarta, Indonesia
}

\begin{abstract}
Lead Rubber Bearing (LRB) has been widely applied for seismic protection of mid and high-rise buildings around the world. Its excellent energy dissipation becomes the most important aspect of this isolation system thanks to the plasticity and recovery behavior of the lead core. Aiming to develop a deeper knowledge on the behavior of LRB's, a 3D detailed finite element (FE) modeling is performed in Abaqus FE software. Some important parameters involved in the model are plasticity of the lead core and hyper-elasticity and viscosity of the rubber material. The parameters for rubber material are derived from the results of experimental works in the laboratory, including uniaxial tensile test and relaxation test. The bearing model is then subjected to a cyclic shear-test under constant vertical load. The result of the 3D-FE model is then compared with the analytic-Abaqus model for LRB isolators, developed in the literature. Finally, both 3D-FE model and analytic model result in a good agreement on the shear behaviour of the presented LRB.
\end{abstract}

\section{Introduction}

Base isolation system has been used widely to reduce the effect of an earthquake by damping the vibration of the structures which means reducing the frequency of the building or in other words increasing its period [1-3]. The use of base isolation system has also been developed for low-rise buildings including one- or two-story residential houses. For highrise buildings, the use of regular base isolation which has low damping properties does not accommodate the requirements during the severe earthquake [4-6]. The demand for high damping isolation system for seismic protection of buildings and bridges is increasing. Lead Rubber Bearing (LRB) is one of base isolation with high damping capability thanks to the main contribution of the lead core during shear displacement and sometimes with a combination of high-damping rubber. Lead rubber bearing consists of laminated rubber pads with steel reinforcement to improve only the vertical stiffness against the axial load. In mid-point of diameter, a cylinder lead core is placed as the dissipative device.

The LRB has been widely applied around the world, particularly in developed countries with high seismic risk, such as Japan, China, and Italy for bridges and buildings protection $[7,8]$. The remarkable feature of LRB is the high energy dissipation behavior thanks to the

*Corresponding author: tavio_w@yahoo.com 
plastic behavior of the lead core. The lead core deforms plastically under shear deformations while dissipating energy through heat. The typical value of equivalent damping is about $30 \%$ which is doubled compared to the High Damping Rubber Bearing (HDRB). The LRB device is promising for seismic isolation of buildings both under farfault and near-fault seismic motion [9-11].

The studies of LRBs in literature mainly discuss the LRB device using low-damping rubber $[12,13]$. Therefore, the energy dissipation contribution of rubber is often neglected. However, the author finds the utilization of high-damping rubber (10\% of damping) in the commercial product [14]. Thus in the FE modeling, in addition to the plasticity properties of the lead core, the viscosity model is required for the rubber element.

Hyperelasticity and viscosity model for rubber is a fundamental aspect in elastomeric isolator modeling. In this study, a series of experimental work is conducted to characterize the properties of the rubber material. The specimen considered is rubber with $0.4 \mathrm{MPa}$ of shear modulus and about $10 \%$ of equivalent damping, which is considered as a high damping material. A uniaxial tensile test and a relaxation test are required to determine the parameters of hyperelasticity and viscosity, respectively.

In the Abaqus 3D FE modeling, the hyperelasticity of rubber follows the Yeoh model [15] and the viscosity is characterized by Prony-series model [16, 17]. Those two models require an optimization process of the experimental data. The isolator model is then subjected to a cyclic shear test under a constant vertical load, which corresponds to the design load. Finally, the result of 3D FE modeling makes a good agreement with the target properties from the manufacturer. Through this 3D FE model, we can observe in detail the stress distribution in the isolator elements.

This paper also discusses the method for structural analysis involving LRBs in Abaqus software. Applying a 3D FE model for many isolators on a structure will be computationally expensive. Therefore, a simplified Abaqus User-Element (UEL) available in the literature is used to represent the behavior of LRBs in structural analyses. A good agreement on shear behavior is shown by the UEL model compared to the $3 \mathrm{D}$ FE model. This UEL is considerably helpful for structural analyses in Abaqus environment.

\section{Rubber and lead core material properties}

\subsection{Rubber properties}

Rubber material considered in this work has $0.4 \mathrm{MPa}$ of shear modulus and $10 \%$ of equivalent viscous damping, which is categorized as a high-damping rubber. Rubber is well known for the non-linear elastic behavior, namely hyper-elasticity. Many researchers researched to develop the appropriate model of rubber hyperelasticity. In order to determine the hyper-elasticity properties, a series of uniaxial tensile test on dumb-bell rubber specimen is performed in the laboratory. Fig. 1 shows the strain-stress curve of the rubber specimen (black line).

A Yeoh hyperelasticity model is chosen as the mechanical model of the rubber, as seen in Eq. 1 [15]. Where $W$ is the strain energy per unit of volume, $C_{i 0}$ and $D_{i}$ are material parameters, $I_{l}$ is the first deviatoric strain invariant, and Jel is the elastic volume ratio. Through an optimization procedure, some hyper-elasticity coefficients are obtained, as seen in Table 1. Fig. 1(a) also shows an excellent agreement of strain-stress curve between test data and Yeoh model.

$$
W=\sum_{i=1}^{3} C_{i 0}\left(I_{1}-3\right)^{i}+\sum_{i=1}^{3} \frac{1}{D_{i}}\left(J_{e l}-1\right)^{2 i}
$$


The other important mechanical properties are the damping behavior of the rubber. The parameters can be derived through a relaxation test with high-speed traction. Thus, in the laboratory the dumb-bell rubber specimen with $10 \%$ of damping is pulled as fast as possible and then its internal stress is recorded for several minutes. In this case, $40 \mathrm{~mm} / \mathrm{s}$ of traction is the maximum speed that the device can perform. The specimen is stretched up to $100 \%$ and then is held for 100 seconds, while the device records the evolution of stress. Fig. 1(b) shows the normalized stress in function of time (black line) during the constantly maintained strain. In Abaqus FE model, the viscosity of the rubber can be characterized through Prony-series model, see Eq. 2 [16,17]. Where $G(t)$ is the current stress, $G_{0}$ is the initial stress, $t$ is time, and $G_{i}$ and $t_{i}$ are the Prony coefficients.

$$
G(t)=G_{0}+\sum_{i=1}^{N} G_{i} \cdot \exp \frac{-t}{t_{i}}
$$

An optimization is performed to obtain the Prony model as presented in Table 2. The comparative curve between relaxation data and Prony model can be seen in Fig 1(b).

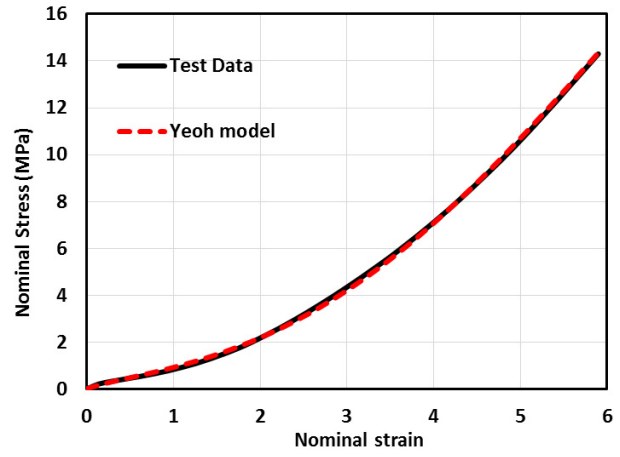

(a)

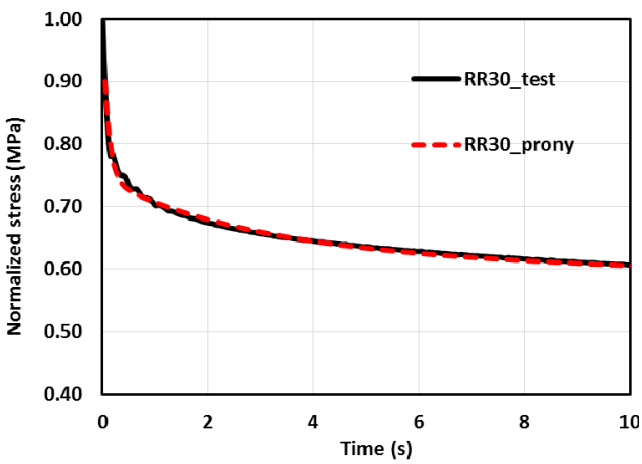

(b)

Fig. 1. The experimental results (black line) of uniaxial tensile test (a) and relaxation test (b) of the rubber specimen with the corresponding numerical models (red line).

Table 1. Yeoh hyperelasticity parameters for rubber material.

\begin{tabular}{|c|c|c|}
\hline $\mathbf{C}_{\mathbf{1 0}}$ & $\mathbf{C}_{\mathbf{2 0}}$ & $\mathbf{C}_{\mathbf{3 0}}$ \\
\hline 0.206 & 0.013 & -0.000059 \\
\hline
\end{tabular}

Table 2. Prony-series coefficients for rubber specimen.

\begin{tabular}{|c|c|c|}
\hline $\boldsymbol{i}$ & $\boldsymbol{G}_{\boldsymbol{i}}$ & $\boldsymbol{t}_{\boldsymbol{i}}$ \\
\hline 1 & 0.25 & 0.103 \\
\hline 2 & 0.11 & 2.664 \\
\hline 3 & 0.08 & 26.06 \\
\hline 4 & 0.25 & 924.24 \\
\hline
\end{tabular}




\subsection{Lead core properties}

The lead core contributes significantly to the damping behavior of the LRB isolator. In this study, the Young modulus and Poisson ration of the lead material are $15 \mathrm{MPa}$ and 0.32 , respectively. Meanwhile, the plasticity model of the lead is presented in Fig. 2.

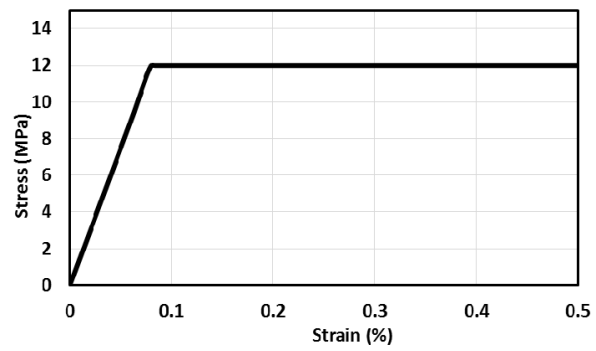

Fig. 2. Elastic-plastic models of the lead core material.

\section{The 3d Finite element modeling}

The isolator considered in this study is a commercial type in the literature [14]. The dimension and target properties of the isolator is shown in Table 3. The elastomeric isolator is reinforced by steel reinforcements to improve only the vertical stiffness against the axial load from the structure. The Young modulus and Poisson ratio of the steel are $210 \mathrm{GPa}$ and 0.25 , respectively.

Table 3. Dimension properties of the presented LRB.

\begin{tabular}{|l|c|}
\hline Outer diameter $(d o)$ & $350 \mathrm{~mm}$ \\
\hline Lead diameter $(d l)$ & $60 \mathrm{~mm}$ \\
\hline Thickness of single rubber pad $(t r)$ & $7 \mathrm{~mm}$ \\
\hline Total number of rubber pad $(n r)$ & 15 \\
\hline Thickness of steel reinforcement $(n s)$ & $0.5 \mathrm{~mm}$ \\
\hline Total thickness of rubber $(h r)$ & $105 \mathrm{~mm}$ \\
\hline Horizontal stiffness & $0.49 \mathrm{kN} / \mathrm{mm}$ \\
\hline Equivalent damping & $28 \%$ \\
\hline
\end{tabular}

Fig. 3 shows the meshing procedure of the isolator. All parts are meshed using C3D8R elements of different size. Rubber, steel reinforcement, and lead are modeled with refined mesh to facilitate high deformability. Meanwhile, a coarse mesh is implemented for the rigid steel supports. The material properties of rubber and lead obtained from section 2 is then implemented in the FE model. For boundary conditions, the surface bonding between all parts in the isolator unit is considered perfectly tied. This is rather a simplification because the LRB product usually does not have any cohesive bonding between the leadcore and the surrounding parts. However, in 3D FE analyses, implementing a frictional contact between the lead and other parts will increases significantly the computational time. 
Such simplification will not give any remarkable difference in the simulation result, as reported in the literature [12].

The isolator unit is then subjected to a 0.5 cyclic test under a constant vertical load of $600 \mathrm{kN}$, which corresponds to the maximum design load. During the shear test, the upper steel support is restrained from the rotation to represent the test condition in the laboratory. The deformation patterns and shear behavior of the LRB are presented in Fig. 4 and 5. The equivalent damping of the isolator can be computed through Eq. 3 and 4 [18], where $\xi$ is equivalent damping, W.d represents the dissipative energy (the area inside the hysteresis loop), $K_{\text {H.eff }}$ is effective horizontal stiffness (see Fig. 5), and $\Delta_{\max }$ is the maximum displacement. The FE modeling results in $26.8 \%$ of damping and $0.52 \mathrm{kN} / \mathrm{mm}$ of effective horizontal stiffness, which have a good agreement with the target properties of the commercial product [14], see Table 4.

$$
\begin{gathered}
\xi=\frac{W \cdot d}{4 \cdot \pi \cdot W_{s}} \\
W_{s}=\frac{K_{H, \text { eff }} \cdot \Delta_{\max }^{2}}{2}
\end{gathered}
$$

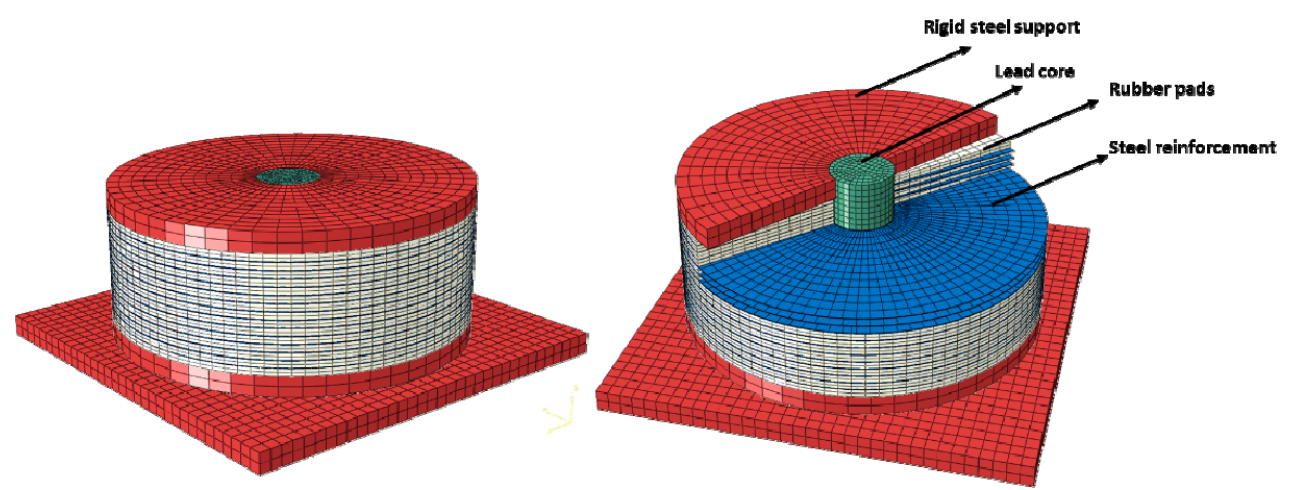

Fig. 3. Meshing method and elements of the LRB.

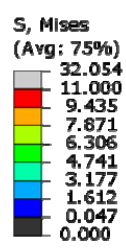

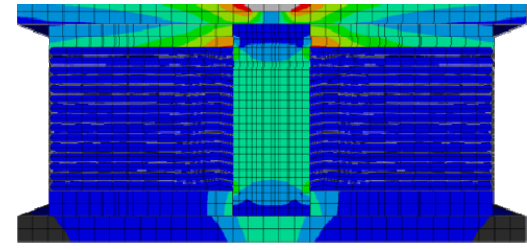

$0 \%$ of shear

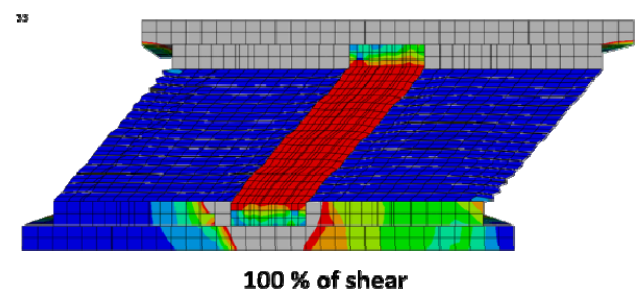

$100 \%$ of shear

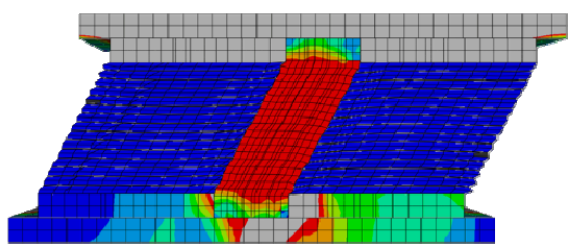

$50 \%$ of shear
Fig. 4. Deformation patterns of the LRB during shear test simulation with the corresponding Von Mises stress. 
Table 4. Comparative results between manufacture products, 3D FE model, and UEL model

\begin{tabular}{|c|c|c|c|}
\hline & Manufacture & 3D-FE Model & UEL Model \\
\hline Effective horizontal stiffness & $0.49 \mathrm{kN} / \mathrm{mm}$ & $0.52 \mathrm{kN} / \mathrm{mm}$ & $0.48 \mathrm{kN} / \mathrm{mm}$ \\
\hline Equivalent damping & $28 \%$ & $26.8 \%$ & $27.8 \%$ \\
\hline
\end{tabular}

\section{Abaqus user element (UEL) for LRBs}

Abaqus is one of powerful FE software used widely for structural and material analyses. Its feature to present the evolution of local stress and damage of the structural elements becomes the important aspect for structural engineers. In case of structural modeling involving LRB isolators in Abaqus, using detailed 3D FE model for a single isolator will be computationally expensive and tends to be unfeasible. Therefore, researchers developed a User Element (UEL) model of LRB for use in Abaqus environment [13]. This UEL model of LRB will significantly decrease the computational time compared to the 3D FE model.

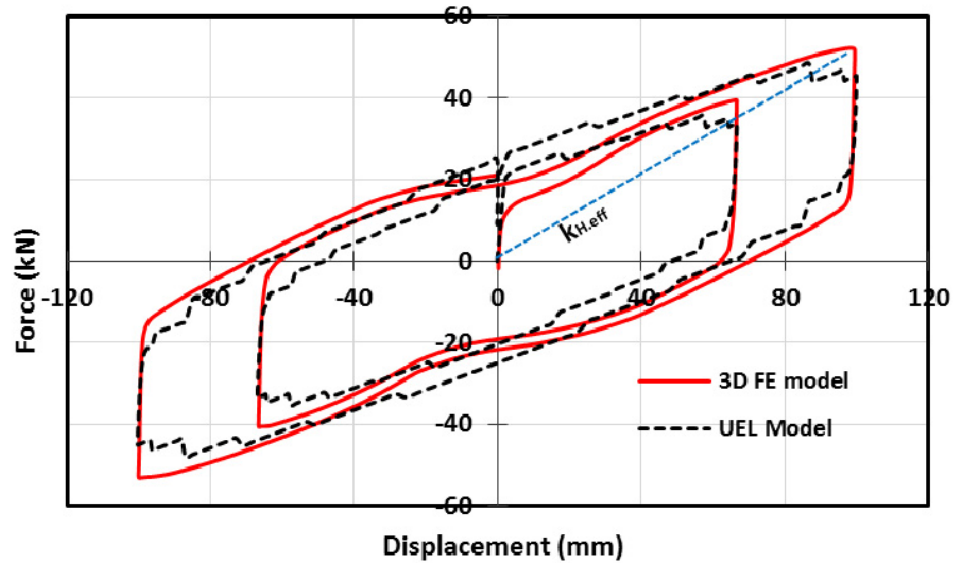

Fig. 5. Shear behavior of the LRB obtained from 3D FE model and UEL model.

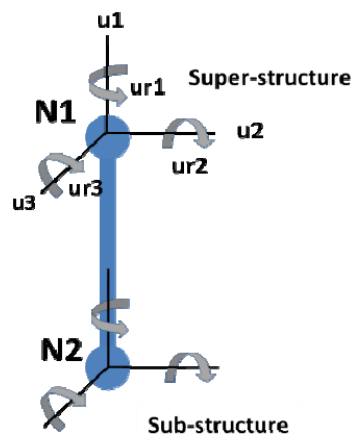

(a)

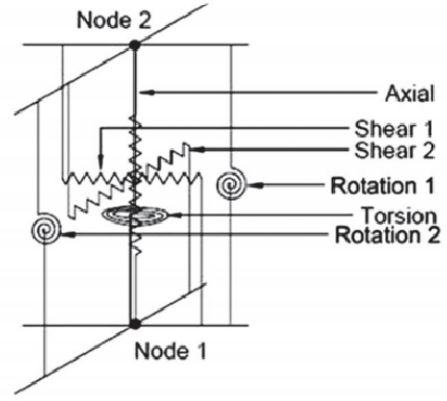

(b)

Fig. 6. (a) Degree of freedom and (b) rheological model of the User Element for LRB in Abaqus [13]. 
The UEL presented in the literature [13] is in the form of FORTRAN user subroutine and can be used easily by inputting some mechanical properties and dimensions of the isolator in the input file. The derived parameters such as critical load and stiffness of the bearing are computed inherently in the UEL formula. The UEL contains 12 DOFs so that all 3D behavior of the LRB isolator can be captured, see Fig. 6 .

In this section, the result of shear test simulation using UEL model is compared to the 3D-FE model to evaluate its performance. Finally, Fig. 5 and Table 4 show an excellent performance of the UEL model in predicting the shear behavior of the LRB. This UEL model is practical and helpful for structural analyses in Abaqus environment.

\section{Conclusions}

A 3D FE modeling of Lead Rubber Bearing (LRB) using high damping material is performed in this work. The elastic behavior of the rubber is characterized based on Yeoh hyperelasticity model, while the high damping of the rubber is characterized using Pronyseries model. The hyperelastic and damping properties of the rubber are obtained through a uniaxial tensile test and relaxation test, respectively. To obtain the corresponding damping behavior of the rubber during a seismic action, the relaxation test is performed by applying high-speed traction to the rubber specimen. In this study, the maximum speed of the tensile device is $40 \mathrm{~mm} / \mathrm{s}$.

The isolator is then modeled in Abaqus using refined mesh for rubber, steel reinforcement, and lead core to facilitate high deformability [19]. The result of FE simulation has a good agreement with the target properties stated in the manufacture, in terms of equivalent damping and effective horizontal stiffness.

In addition, this work also evaluates the User Element (UEL) for LRB modeling, presented in the literature. This UEL for LRB can reduce significantly the computational efforts for structural analyses in Abaqus environment. The UEL discussed is based on Fortran user subroutine and can be easily used by inputting some important properties of the LRB isolator. Finally, the UEL model gives an excellent performance in predicting the behavior of LRB and it is effective for large structural analyses.

\section{References}

1. A.B. Habieb, G. Milani, Tavio, F. Milani, Open Civil Eng. J. 11 M2 (2017)

2. A.B. Habieb, G. Milani, Tavio, Eng. Fail. Analysis 90 (2018)

3. A.B. Habieb, G. Milani, Tavio, F. Milani, AIP Conference Proceedings (2017)

4. A.B. Habieb, G. Milani, Tavio, F. Milani, AIP Conference Proceedings (2017)

5. A.B. Habieb, G. Milani, Tavio, F. Milani, WIT Trans. on the Built Env. 172 (2017)

6. A.B. Habieb, G. Milani, Tavio, F. Milani, AIP Conference Proceedings (2018)

7. A. Martelli, M. Forni, P. Clemente, Proc. of the Structural Engineering World Congress SEW5 (2012)

8. W.-I. Liao, C.-H. Loh, B.-H. Lee, Eng. Struct. 26 (2004)

9. V. Calugaru, M. Panagiotou, Earthq. Eng. \& Struct. Dyn. 43 (2014)

10. M. Bhandari, S.D. Bharti, M.K. Shrimali, T.K. Datta, J. of Earthq. Eng. 22 (2018)

11. R.S. Jangid, Eng. Struct. 29 (2007)

12. I.N. Doudoumis, F. Gravalas, N.I. Doudoumis, $5^{\text {th }}$ GRACM International Congress on Computational Mechanics (2005) 
13. M. Kumar, A.S. Whittaker, M.C. Constantinou, Seismic isolation of nuclear power plants using elastomeric bearings (University of Buffalo, New York, 2015)

14. Alga-Spa, High Damping Rubber Bearings and Lead Rubber Bearings Catalogue https://www.elemka.gr/Uploads/materials/4.3 proionta efedrana/4.3.4_Seismikis\%20monosis/ALGASISM_HDRB_AND_LRB.pdf. (2018)

15. M. Shahzad, A. Kamran, M.Z. Siddiqui, M. Farhan, Mat. Res. 18 (2015)

16. M.H.R. Ghoreishy, Mat. \& Design 35 (2012)

17. D.S. Simulia, ABAQUS 6.13 User's Manual (Dassault Systems, Providence, RI, 2013)

18. H. Toopchi-Nezhad, M.J. Tait, R.G. Drysdale, Struct. Control and Health Monitor. 15 (2008)

19. I.V. Kalpakidis, M.C. Constantinou, A.S. Whittaker, Earthq. Eng. \& Struct. Dyn. 39 (2010) 